\title{
Self-assembled pullulan-silica oxygen barrier hybrid coatings for food packaging applications
}

\begin{tabular}{|r|l|}
\hline Journal: & Journal of Agricultural and Food Chemistry \\
\hline Manuscript ID: & jf-2011-04033d.R1 \\
\hline Manuscript Type: & Article \\
\hline Date Submitted by the & n/a \\
\hline Complete List of Authors: & $\begin{array}{l}\text { Farris, Stefano; University of Milan, Food Science and Microbiology } \\
\text { Introzzi, Laura; University of Milan, Food Science and Microbiology } \\
\text { Fuentes-Alventosa, José María; Centro de Investigación y Formación } \\
\text { Agraria "Alameda del Obispo", Instituto de Investigación y Formación } \\
\text { Agraria y Pesquera (IFAPA) } \\
\text { Santo, Nadia; University of Milan, Interdepartmental Center of } \\
\text { Advanced Microscopy } \\
\text { Rocca, Roberto; Metalvuoto Spa, } \\
\text { Piergiovanni, Luciano; University of Milan, Food Science and } \\
\text { Microbiology }\end{array}$ \\
\hline & \\
\hline
\end{tabular}

\section{SCHOLARONE Manuscripts}




\section{Self-assembled pullulan-silica oxygen barrier hybrid coatings for food packaging applications}

Stefano Farris ${ }^{* a}$, Laura Introzzi ${ }^{\mathrm{a}}$, José Maria Fuentes-Alventosa ${ }^{\mathrm{a}, \mathrm{b}}$, Nadia Santo ${ }^{\mathrm{c}}$, Roberto Rocca ${ }^{\mathrm{d}}$, Luciano Piergiovanni $^{\mathrm{a}}$

${ }^{a}$ DiSTAM, Department of Food Science and Microbiology, Packaging Division, University of Milan, Via Celoria 2 - 20133 Milan, Italy

${ }^{b}$ Centro de Investigación y Formación Agraria "Alameda del Obispo". Instituto de Investigación y Formación Agraria y Pesquera (IFAPA). Avda. Menéndez Pidal s/n. 14004 Córdoba, Spain

${ }^{c}$ Interdepartmental Center of Advanced Microscopy, CIMA, University of Milan Via Celoria $26-20133$ Milan, Italy

${ }^{d}$ Metalvuoto Spa, Via L. da Vinci 3 - 20040 Milan, Italy

*Corresponding author. Tel.: +39 0250316654; Fax: +39 0250316672

Email address: stefano.farris@ unimi.it (S. Farris) 
1 ABSTRACT. The scope of this study encompassed the evaluation of pullulan as a suitable

2 biopolymer for the development of oxygen barrier coatings to be applied on polyethylene

3 terephthalate (PET), especially for food packaging applications. To enhance the oxygen barrier

4 properties of the organic phase (pullulan) even at high relative humidity values, an inorganic

5 phase (silica), obtained through in situ polymerization, was also utilized to obtain hybrid

6 coatings using the sol-gel technique. Transmission electron microscopy (TEM) images and

7 Fourier transform infrared (FT-IR) spectra showed that mixing the two phases yielded a three-

8 dimensional hybrid network formed by self-assembly and mediated by the occurrence of new

9 hydrogen bond interactions at the inter-molecular level, although the formation of new covalent

10 bonds could not be excluded. The deposition of the hybrid coatings decreased the oxygen

11 transmission rate (OTR) of the plastic substrate by up to two orders of magnitude under dry

12 conditions. The best performance throughout the scanned humidity range $(0 \%-80 \%$ relative

13 humidity) was obtained for the formulation with the lowest amount of silica (that is, an 14 organic/inorganic ratio equal to 3).

18 KEYWORDS: Fourier transform infrared (FT-IR) spectroscopy; oxygen transmission rate 19 (OTR); packaging; pullulan; transmission electron microscopy (TEM) 
22

23

24

25

26

27

\section{Introduction}

Pullulan, an exopolysaccharide (EPS) produced by the yeast-like forms of the fungus Aureobasidium pullulans, is a regularly repeating copolymer $\{\rightarrow 6)-\alpha-\mathrm{D}$-glucopyranosyl-( $1 \rightarrow 4)$ $\alpha$-D-glucopyranosyl-( $1 \rightarrow 4)$ - $\alpha$-D-glucopyranosyl- $(1 \rightarrow\}_{n}$, that can be viewed as a succession of

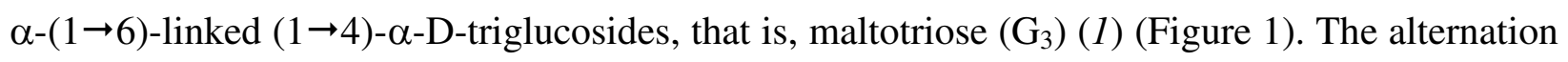
of $(1 \rightarrow 4)$ and $(1 \rightarrow 6)$ bonds is responsible for the two principal features of pullulan, namely structural flexibility (centered on the $\alpha-1 \rightarrow 6$-linkages) and enhanced solubility $(2,3)$. The hydroxyl groups extensively distributed along its skeleton not only enable pullulan to easily establish hydrogen bonds with other polar molecules, but also make this polysaccharide suitable for many derivatizations, including esterification, etherification, hydrogenation, and carboxylation (4).

Pullulan is soluble in both cold and hot water, insoluble in organic solvents, odorless, tasteless, non-toxic, and biodegradable, with good adhesive and binding properties as well as oxygen barrier properties under dry conditions (5). The main applications of pullulan pertain to the health care (lotions, shampoos, oral care), pharmaceutical (denture adhesives, capsules for dietary supplements, sustained-release formulations), and food (binder and stabilizer in food pastes, edible films, and protective glaze on foods) industries (6). More advanced applications include the recent development of pullulan-based antimicrobial active packaging systems (7) and pullulan-functionalized electrospun nanofibers (8).

In spite of its appealing peculiarities and all of the aforementioned applications, pullulan is still an under-exploited biopolymer, mainly due to its high cost. Currently, pullulan is quoted at $28 € / \mathrm{kg}$, that is, approximately three times higher than the price of other polysaccharides, such as dextran and xanthan, and approximately five times higher than the price of a synthetic oil- 
45 derived oxygen barrier polymers, such as polyvinyl alcohol (PVOH). The removal of melanin

46 pigments during the downstream process and the limited scale of pullulan production are the two

47 major factors that determine production costs $(6)$. Therefore, new enhanced strains, engineering

48 innovations, and novel applications might improve the economics of pullulan production and 49 expand its market penetration.

50 Among other opportunities, the food packaging field is being considered with renewed

51 interest, in particular with respect to the development of bio-based materials (9). In this respect,

52 coating technology has attracted (and still attracts) the attention of many researchers attempting

53 to obtain structures with either new features (e.g., antimicrobial coatings) (10) or improved

54 properties (e.g., barrier properties) (11). Coating technology applied to biomacromolecules

55 involves the use of water solutions/dispersions with a concentration ranging approximately from

563 wt.\% to 15 wt.\% depending on the characteristics (e.g., molecular weight) of the selected

57 molecule. These solutions are then deposited onto different substrates (e.g., flexible plastic films)

58 through different techniques, among which the gravure coating technique seems to afford a

59 number of advantages over other techniques (e.g., reverse roll coaters, calendar coaters, knife-

60 over-roll coaters, blade coating, wire-wound rod coater). One important advantage is that he

61 removal of the solvent, generally achieved by hot air and infrared lamps, is facilitated by the thin

62 coating thickness achieved by gravure coating (usually from 0.2 to $2 \mu \mathrm{m})$ (12).

The development of new oxygen barrier biopolymer coatings for plastic substrates is

64 becoming an intriguing field of application, especially in view of the possibility of replacing

65 commonly used synthetic polymers (for example, PVOH, ethylene vinyl alcohol - EVOH, and

66 polyvinylidene chloride - PVDC) with new formulations originating from agricultural and

67 renewable resources (13). This approach has also been suggested as a valuable and promising 
way to manage waste disposal issues (14). Owing to its inherent good oxygen barrier properties, pullulan is a valid candidate for the design of new coatings, and would be specifically suitable for the protection of readily oxidized fats and vitamins in foods. However, before this goal can be achieved, a major drawback needs to be addressed: its water sensitivity, due to the hydrophilic hydroxyl groups distributed along the pullulan backbone (15). Therefore, to make these biopolymer coatings successful for a broader range of relative humidity (which appears to be more realistic than a fixed-humidity condition), further research in this area must be encouraged.

The aim of this study was to develop coatings for conventional plastic packaging materials using pullulan as the organic phase to provide the necessary oxygen barrier, in combination with tetraethoxysilane (TEOS), a metal alkoxide precursor of silica used as the inorganic counterpart and intended to provide resistance to humidity. The hypothesis was that pullulan can successfully mimic organic, petrol-derived polymers in its interaction with the inorganic phase to form high oxygen barrier hybrid coatings. Based on the literature, this is the first work envisaging the use of pullulan as a biopolymer coating directly applied on a plastic substrate. This could pave the way for a new alternative to the petrol-based coatings currently available on the market of food packaging plastics.

\section{Fundamental chemistry underlying in situ development of pullulan-silica hybrids}

Some aspects of theory linked to metal alkoxide chemistry and its potential interactions with pullulan are summarized hereinafter to better clarify the justifications of this study. The significant chemical reactions involved in the formation of the hybrid network between TEOS and pullulan are summarized in Figure 2. The hydrolysis of the metal alkoxide, which is the first step of the overall reaction, occurs due to the nucleophilic attack of the oxygen contained in water on silicon atoms (16). However, protonation of the alkoxide groups is faster if an acid 
91 (e.g., $\mathrm{HCl}$ ) is used as a catalyst (17), although base-catalyzed hydrolysis is also well established 92 (18). Owing to the hydrolysis reaction, the alkoxide groups (-OR) are replaced with hydroxyl 93 groups $(-\mathrm{OH})$ to form silanol compounds, $\mathrm{Si}(\mathrm{OH})_{\mathrm{n}}$, where ethanol is the by-product. Upon 94 hydrolysis, the $\mathrm{Si}(\mathrm{OH})_{\mathrm{n}}$ groups may react according to a typical condensation scheme by two different routes (water condensation and alcohol condensation) to yield in both cases $\mathrm{SiO}_{2}$ covalent bonds and either water or alcohol as by-products. However, due to molecular constraints, $\mathrm{Si}-\mathrm{O}-\mathrm{Si}$ linkage formation is typically about $80-85 \%$ of the theoretical value (19). In the presence of pullulan, in addition to the condensation reactions, $\mathrm{Si}(\mathrm{OH})_{\mathrm{n}}$ groups arising from TEOS can interact via hydrogen bonds with the pendant polar groups (e.g., hydroxyl groups) along the backbone of the biopolymer to yield the hybrid network as reported in the

101 downwards scheme of Figure 2. The formation of covalent bonds between the hydroxyl groups 102 and the silanol groups has also been postulated $(20,21)$. Whether these two routes (i.e., the 103 condensation reaction and hydrogen bond formation) proceed simultaneously or not depends 104 strictly on many factors, and relies especially on the concentration of the reagents and the $\mathrm{pH}$ of 105 the medium. The expected final result is a new material that should share the attributes of each 106 individual phase, such as the oxygen barrier property of pullulan and the resistance to moisture 107 of the glass-like inorganic component.

\section{Experimental Section}

109 Materials. High purity tetraethoxylane (Sigma-Aldrich, Milan, Italy) was used as the metal 110 alkoxide precursor of the inorganic phase; $1 \mathrm{M}$ hydrochloric acid (Sigma-Aldrich, Milan, Italy) 111 was used as the catalyst; pullulan powder (PF-20 grade, $\mathrm{M}_{\mathrm{n}} \sim 200 \mathrm{kDa}$; Hayashibara

112 Biochemical Laboratories Inc., Okayama, Japan) was employed as the organic system. All 113 materials were used as received for the preparation of the hybrid solution. Ethanol $(96 \% \mathrm{v} / \mathrm{v}$; 
114 Sigma-Aldrich, Milan, Italy) and Milli-Q water $(18.3 \mathrm{M} \Omega \cdot \mathrm{cm})$ were used as the only solvents 115 throughout the experiments. Reagent grade lithium chloride anhydrous ( $\mathrm{LiCl})$, potassium acetate $116\left(\mathrm{CH}_{3} \mathrm{COOK}\right)$, magnesium chloride hexahydrate $\left(\mathrm{MgCl}_{2} \cdot 6 \mathrm{H}_{2} \mathrm{O}\right)$, potassium carbonate $\left(\mathrm{K}_{2} \mathrm{CO}_{3}\right)$, 117 magnesium nitrate hexahydrate $\left[\mathrm{Mg}\left(\mathrm{NO}_{3}\right)_{2} \cdot 6 \mathrm{H}_{2} \mathrm{O}\right]$, lithium acetate dihydrate $\left(\mathrm{C}_{2} \mathrm{H}_{3} \mathrm{LiO}_{2} \cdot 2 \mathrm{H}_{2} \mathrm{O}\right)$, 118 sodium chloride $(\mathrm{NaCl})$, potassium nitrate $\left(\mathrm{KNO}_{3}\right)$ (Sigma-Aldrich, Milan, Italy) were all used to 119 prepare the saturated salt solutions, giving theoretical water activity $\left(a_{w}\right)$ values of $0.11,0.23$, 120 $0.32,0.44,0.52,0.66,0.75$, and 0.92 at $25 \pm 0.2^{\circ} \mathrm{C}$, respectively.

121 Preparation of hybrid coatings. In the first step, an acidic $(\mathrm{pH}=2.0 \pm 0.8)$ hydroalcoholic (30 122 wt-\% ethanol) solution of TEOS was prepared by using $1 \mathrm{M} \mathrm{HCl}(0.78 \mathrm{wt}-\%)$ as a catalyst. In 123 this step, the $\mathrm{H}_{2} \mathrm{O}$ :TEOS molar ratio was fixed at 4:1. The hydrolysis of TEOS was carried out at 124 room temperature for approximately 1 hour. At the same time, a water dispersion of pullulan was 125 prepared at room temperature according to the concentrations reported in Table 1 by mixing the 126 polysaccharide with the solvent by means of rapid stirring (1500 rpm x 1 hour). The $\mathrm{pH}$ of the 127 final pullulan water dispersions ranged between $5.0 \pm 0.05$ for the highest pullulan concentration 128 (i.e., formulation $\mathrm{H}_{0}$ ) and $5.65 \pm 0.08$ for the lowest pullulan concentration (i.e., formulation $129 \mathrm{H}_{0.5}$ ). In the second step, the inorganic and organic phases were mixed together for 1 hour, in 130 order to allow the formation of the hybrid network. The composite solutions were then deposited 131 by roll-coating onto $12 \pm 0.5 \mu \mathrm{m}$-thick polyethylene terephthalate (PET) films (Toray Saehan, 132 Kyungbuk, South Korea) using an automatic applicator (Ref. 1137; Sheen Instruments, 133 Kingston, UK), equipped with a steel horizontal wire-wound rod of $18 \mathrm{~cm}$ width (Ref. 1120; 134 Sheen Instruments, Kingston, UK), to obtain a wet coating thickness of approximately $10 \mu \mathrm{m}$ 135 (data provided by the factory). Coating deposition was performed according to ASTM D823-07 136 - Practice C (22), at a constant speed of $150 \mathrm{~mm} \mathrm{~min}^{-1}$. With the goal of investigating the 
137 influence of the organic/inorganic ratio [O/I, defined as the pullulan/( $\mathrm{SiOH})_{4}$ weight ratio for a 138 complete hydrolysis process] on the final oxygen barrier properties of the hybrid coatings, six 139 different solutions were prepared by varying the O/I ratio of the coating from 100/0 to 50/100, as 140 reported in Table 1 . Both solvent evaporation and the progress of the reactions leading to the 141 hybrid network formation were obtained by storing the coated PET films in a vacuum oven at $14240^{\circ} \mathrm{C}$ for 24 hours.

143 Residual moisture. The residual moisture of the coatings after drying was measured by means 144 of a halogen moisture analyzer, mod. HG63 (Mettler Toledo, Zurich, Switzerland).

145 Thickness determination. A $10 \times 10 \mathrm{~cm}$ sample (plastic substrate + coating) was cut and 146 weighed $\left(M_{1}, \mathrm{~g}\right)$. The coating was then mechanically removed by immersion in hot water $\left(80^{\circ} \mathrm{C}\right)$ 147 and the resulting substrate film was weighed $\left(M_{2}, \mathrm{~g}\right)$. The apparent thickness $(\mu \mathrm{m})$ of the coating 148 149 was obtained according to the following equation (14):

$$
l=\frac{M_{1}-M_{2}}{\rho} \times 100
$$
where $\rho\left(\mathrm{g} \mathrm{cm}^{-3}\right)$ is the density of the aqueous dispersion. Three replicates were analyzed for each biopolymer composition. In order to check for the consistency of the obtained results, the thickness of both uncoated and coated PET films was also measured with a micrometer 153 (Dialmatic DDI030M; Bowers Metrology, Bradford, UK) to the nearest $0.001 \mathrm{~mm}$ at 10 different 154 random locations. Finally, a rough indication of the thickness of both coatings and substrate was 155 achieved using an optical microscope (OM) (Micro Nikon Eclipse ME600 Laboratory Imaging; 156 Nikon Instruments, Sesto Fiorentino, Italy) at 50× magnification (Figure 3). In this case, films 157 after storage in the vacuum oven were fixed on a rectangular steel sample holder and a sharp razor blade was then used to cut them lengthwise, permitting the observation of the cross section 
159 of the composite films. Finally, the thickness of the layers was measured using NIS-Element 160 software (Nikon Instruments, Sesto Fiorentino, Italy).

161 Fourier Transform Infrared - Attenuated Total Reflectance (FTIR-ATR). The structural 162 characteristics and chemical bonding of the coatings at different $\mathrm{O} / \mathrm{I}$ ratios were investigated by a 163 PerkinElmer FT-IR Spectrum 100 Series spectrometer (PerkinElmer, Waltham, MA, USA) 164 equipped with a universal attenuated total reflectance (UATR) accessory featuring a single165 reflection sampling plate with a $1.8 \mathrm{~mm}$ round germanium surface. To ensure satisfactory 166 physical contact took place between the samples and the crystal surface, a high-pressure 167 clamping device was used. Spectra were recorded at room temperature within the range of 650$1684000 \mathrm{~cm}^{-1}$ at $4 \mathrm{~cm}^{-1}$ resolution. Spectrum 6.0 software was used for data acquisition and analysis.

169 Moisture sorption properties. To provide evidence of improved moisture resistance of the 170 hybrid coatings compared to the pure pullulan coatings, moisture sorption data were collected 171 according to the procedures reported in the COST project of European Cooperation in the field 172 of Technical and Scientific Research and the principles described by Bell and Labuza (23). For 173 this purpose, approximately $4 \mathrm{~g}$ of each coating formulation were initially kept for three weeks in 174 a glass desiccator containing Drierite ${ }^{\circledR}$, and then moved to sealed glass jars containing saturated 175 salt slurries in the $a_{w}$ range of 0.11 to 0.92 and stored in a refrigerated incubator (mod FOC 176 225E; Velp Scientifica, Usmate, Italy) at $25 \pm 0.2^{\circ} \mathrm{C}$. For all samples, equilibrium was reached in 177 two weeks. The equilibrium moisture content data were then fitted to the Guggenheim178 Anderson-DeBoer (GAB) sorption isotherm model:

$$
M=\frac{C K M_{0}}{\left[\left(1-K a_{w}\right)\left(1-K a_{w}+C K a_{w}\right)\right]} a_{w}
$$


182 the monolayer, respectively, both expressed as $\mathrm{g} / 100 \mathrm{~g}$ of dry matter. $C$ and $K$ are constants

183

184

185

186

187

188

189

190

191

192

193

194

195

196

197

198

199

200

201

202

203 associated with the enthalpies of sorption of the monolayer and multilayer, respectively. In particular, the constant $C$ should always have a positive value, due to the exothermic interaction of water vapor with the primary sorption sites of the hygroscopic matrix, whereas reasonable values of $K$ considerably higher than unity have been never found in the literature. Therefore, the validity of the mathematical model assumed in this work was assessed not only by evaluating its ability to fit the experimental data (hence by the $\mathrm{R}^{2}$ coefficient), but also assuming the physicochemical basis of the water sorption phenomenon.

Microscopy analyses. Transmission electron microscopy (TEM) images were captured to visualize the individual phases (i.e., the inorganic $\mathrm{SiO}_{2}$ and the organic pullulan phases) as well as hybrid network growth. For this purpose, $5 \mu \mathrm{L}$ of the hybrid dispersions were deposited onto a Formvar-coated $\mathrm{Cu}$ grid (400-mesh). After adsorption, the grid was stained with a droplet $(5 \mu \mathrm{L})$ of $1 \%$ uranyl acetate and dried with filter paper. Observations were made using a LEO 912 AB energy-filtering transmission electron microscope (EFTEM) (Carl Zeiss, Oberkochen, Germany) operating at $80 \mathrm{kV}$. Digital images were recorded with a ProScan $1 \mathrm{~K}$ Slow-Scan CCD camera (Proscan, Scheuring, Germany).

The global organization of coated surfaces and the possible presence of fractures on the coated layers were visualized using an optical microscope (OM) (Micro Nikon Eclipse ME600 Laboratory Imaging; Nikon Instruments, Sesto Fiorentino, Italy) at 10× magnification. Pieces of coated films $(30 \times 10 \mathrm{~mm})$ after storage in the desiccator were fixed on a rectangular steel sample holder and observed without any pre-treatment. Image capture and refining were carried out using NIS-Element software (Nikon Instruments, Sesto Fiorentino, Italy). 
204 Oxygen barrier properties. The oxygen barrier properties of both uncoated and coated PET 205 films were assessed on a $50 \mathrm{~cm}^{2}$ surface sample using a MultiPerm permeability analyzer 206 (ExtraSolution ${ }^{\circledR}$ Srl, Navacchio, Italy), according to the standard method ASTM F2622-08 (24), 207 with a carrier flow $\left(\mathrm{N}_{2}\right)$ of $10 \mathrm{~mL} \min ^{-1}$. With the goal of quantifying the influence of the 208 external relative humidity conditions on the barrier properties of coated films, measurements 209 were performed at $23^{\circ} \mathrm{C}$ and at five different relative humidity conditions (i.e., $0 \%, 20 \%, 40 \%$, $21060 \%$, and $80 \% \mathrm{RH})$. The results were expressed as the oxygen transmission rate $\left(\mathrm{OTR}, \mathrm{mL} \mathrm{m}^{-2}\right.$ $21124 \mathrm{~h}^{-1}$ at one atmosphere pressure difference), which has been indicated as the most suitable unit 212 for heterogeneous packaging materials (e.g., multilayer and coated films), that is, whenever a 213 linear relationship between permeability and thickness is not maintained (25). The final OTR 214 values were from three replicates.

215 Statistical analysis

216 The statistical significance of differences in the properties and behaviors of coated films was 217 determined by one-way ANOVA, using JMP 5.0.1 software (SAS Campus Drive, Cary, NC). 218 The mean values, where appropriate, were compared by Student's $t$-test with a significance level $219(p)<0.05$.

\section{Results and Discussion}

221 Residual moisture and coating thickness. As can be seen from the data reported in Table 1, 222 solvent removal upon drying was almost complete regardless of the specific coating formulation. Therefore, the differences detected in the thickness values of the hybrid coatings (Table 1),

224 despite the same solid content equal to $10 \mathrm{wt}-\%$, can be explained considering the increased 225 amount of ethanol (the by-product of the hydrolysis and condensation reactions) as the O/I ratio 
226 decreased. The dilution effect arising from ethanol was thus reflected in the reduced thickness of

227 the hybrid coatings with a higher inorganic phase content.

228 FTIR-ATR analysis. The FTIR-ATR analyses are summarized in Figure 4. Figure 4a and

229 Figure $4 \mathrm{~b}$ display the spectra of coatings collected from pure pullulan and from reacted TEOS

230 (i.e., after hydrolysis and condensation), with the characteristic peaks associated with specific

231 bands in evidence $(26,27)$. Figure 4c and Figure 4d display the two most significant spectral

232 regions where changes occurred in the hybrid coatings at different O/I ratios. An overall

233 visualization of all spectra in the investigated range of $650-4000 \mathrm{~cm}^{-1}$ is provided in the

234 supporting information (see Figure S1). In Figure 4b, the presence of peaks associated with

235 silanol groups $\left(\sim 945 \mathrm{~cm}^{-1}\right)$ and silica $\left(\sim 1060 \mathrm{~cm}^{-1}\right.$ and $\left.\sim 800 \mathrm{~cm}^{-1}\right)$ was clear evidence of the

236 occurrence of both hydrolysis and condensation reactions on the metal alkoxide. The spectra

237 collected from hybrid coatings showed some important changes compared to the pure phases. In

238 the $980 \mathrm{~cm}^{-1}-880 \mathrm{~cm}^{-1}$ region (Figure $4 \mathrm{c}$ ), a band including the two overlapping peaks-

239 corresponding to the silanol groups of TEOS and the $\alpha-(1 \rightarrow 6)$ linkages of pullulan-gradually

240 shifted toward higher wavenumbers as the inorganic phase increased. In addition, as the

241 inorganic phase concentration increased, the peak centered at around $945 \mathrm{~cm}^{-1}$ became

242 increasingly sharper compared to that of reacted TEOS. Correspondingly, the band of the hybrid

243 coatings at around $3300 \mathrm{~cm}^{-1}$ (Figure 4d and Figure S1), associated with hydroxyl group

244 stretching, became broader compared to that of pullulan, while the peak slightly shifted toward

245 lower wavenumbers. It has been pointed out that the simultaneous broadening and shifting of

246 peak absorption area is possibly due to extensive hydrogen bonding between the silanol and

247 hydroxyl groups of the organic phase (28-30). Another indication of the interaction between the

248 hydroxyl groups of pullulan and silanol groups through hydrogen bonds was observed with the 
249 peak centered at $1081 \mathrm{~cm}^{-1}$ for pure pullulan (Figure 4c). As the inorganic concentration 250 increased, a slight shift toward lower wavenumbers (up to $1076 \mathrm{~cm}^{-1}$ for the $\mathrm{H}_{0.5}$ hybrid coatings) 251 occurred, suggesting the possible participation of the hydroxyl groups on $\mathrm{C}_{6}$ of the pullulan 252 backbone in hydrogen bond formation.

Interestingly, the strong sharp band of pullulan at $1021 \mathrm{~cm}^{-1}$ was visible up to the hybrid $254 \mathrm{H}_{1}$, whereas it appeared as a weak shoulder in hybrid coatings $\mathrm{H}_{0.75}$ and $\mathrm{H}_{0.5}$. These latter two, 255 conversely, showed a more pronounced peak at around $1047 \mathrm{~cm}^{-1}$ (i.e., halfway between the two 256 main peaks of reacted TEOS and pullulan, respectively), which apparently seems to be related to 257 the unknown shoulder barely visible in the pullulan spectrum a few wavenumbers before the 258 main peak at $1021 \mathrm{~cm}^{-1}$. A tentative explanation for the appearance of this new peak could be 259 related to the formation of new covalent bonds between the silanol groups and the hydroxyl 260 groups of pullulan. The new peak would thus be associated with the Si-O stretching vibration of 261 the newly formed $\mathrm{Si}-\mathrm{O}-\mathrm{C}$ linkage. Although the formation of new covalent bonds between the 262 silanol groups arising from the hydrolysis of TEOS and the pendant hydroxyl groups of an 263 organic phase (e.g.,. polyvinyl alcohol) has been claimed $(21,28)$, that hypothesis is premature at 264 this time and needs further experimental confirmation.

\section{Moisture sorption isotherms}

266 Moisture sorption isotherms for samples $\mathrm{H}_{0}$ (pure pullulan coating), $\mathrm{H}_{3}$, and $\mathrm{H}_{2}$ are reported in 267 Figure 5. For the three curves, the moisture uptake increased monotonically until a specific $a_{w}(\sim$ 268 0.7) was reached. Above this point, moisture gain rose dramatically due to the dissolution of the 269 crystalline domains by water molecules, which interacted via hydrogen bonds with the hydroxyl 270 groups involved in the formation of the crystalline phase (24). Given that this kind of sorption is 271 mainly driven by surface effects, the dimension of the sample exposed to moisture is a key factor 
272 for proper interpretation of the water content as a function of $a_{w}$. This is why, owing to the

273 extensive shrinking seen in the specimens, which produced specimens of small size after

274 evaporation of the solvent, the moisture sorption properties of the hybrid coatings $\mathrm{H}_{1}, \mathrm{H}_{0.75}, \mathrm{H}_{0.5}$

275 were not assessed.

276

Figure 5 also shows that a lower moisture content for any given $a_{w}$ value was observed for

277 the hybrid coatings $\mathrm{H}_{3}$ and $\mathrm{H}_{2}$, indicating the 'protective' effect of the inorganic phase toward the

278 surrounding moisture. This was also confirmed by the modeling data (Table 2) arising from the

279 fitting procedure of Equation 2 to the experimental sorption measurements. In particular, the 280 moisture content in the monolayer $\left(M_{0}\right)$ predicted by the GAB model was equal to $0.78,0.53$, 281 and $0.19 \mathrm{~g} / 100 \mathrm{~g}$ solids for samples $\mathrm{H}_{0}, \mathrm{H}_{3}$, and $\mathrm{H}_{2}$, respectively, which was consistent with the 282 different silica content of the samples.

283 Hybrid network formation and morphology. Representative TEM images of pure silica, 284 pullulan and the hybrid coating $\mathrm{H}_{1}$ are presented in Figures 6a-d, respectively. Figure 6a displays 285 the $\mathrm{SiO}_{2}$ network after hydrolysis and condensation of the metal alkoxide precursor (i.e., TEOS). 286 As can be seen readily, the inorganic network was formed by silica particles approximately 30$28750 \mathrm{~nm}$ in diameter and well interconnected with one another to form a very tight, compact and 288 ordered structure, which is reflected in the typical high rigidity of silica coatings. Conversely, 289 pullulan molecules (Figure 6b) appeared as thin chains with an estimated diameter of 290 approximately 5-7 nm, with more disordered organization and a remarkable extent of 291 intermolecular folding (entanglement), indicators that have to be linked to the flexibility of high 292 molecular weight chains. The association of the two phases (i.e., organic and inorganic) led to a 293 new scenario. As the O/I ratio increased, the silica network partially lost its original 294 configuration (Figure 6c), being gradually 'disassembled' by the 'permeating' organic phase. 
295 This seems to be confirmed by the image displayed in Figure 6d, where the larger-size silica 296 clusters appear to be twisted by pullulan chains. However, the latter are hardly visible in the 297 same figure (they look like bright ridges), due to the much higher sensitivity of silica to electrons 298 compared to organic molecules. This disaggregation/disruption of the silica network finally led 299 to a more segregated, web-like pattern. Presumably, the reason for this lies in the fact that the 300 addition of pullulan promoted an increase in the $\mathrm{pH}$ of the original TEOS hydroalcoholic 301 solution. It is well established that $\mathrm{pH}$ is a pivotal factor in determining the evolution of silica networks, and thus their final morphology. In particular, it has been pointed out that an increase 303 in $\mathrm{pH}$ yields less-compact networks, with increased inter-chains space (31). The final silica304 pullulan structure can thus be conceived as a self-assembled three-dimensional hybrid network, 305 where the organic and inorganic phases interact spontaneously through intermolecular hydrogen 306 bonding, as also shown by FTIR-ATR.

307 Oxygen barrier properties. The experimental results on the barrier properties are summarized 308 in Table 3, whereas the OTR evolution throughout the $\Delta \mathrm{RH}(\%)$ range of the uncoated substrate 309 (PET), pristine pullulan $\left(\mathrm{H}_{0}\right)$ and the five hybrid coatings considered in this work is displayed in 310 Figure 7. At first glance, it can be seen that all hybrid coatings provided a reduction in the 311 oxygen transmission rate compared to the neat substrate (PET), at least up to $60 \%$ relative 312 humidity (the permeability decrease of PET at high relative humidity is well known and has been 313 described elsewhere) (32,33). In particular, formulation $\mathrm{H}_{3}$ provided, under dry conditions, a 314 remarkable OTR value below $1 \mathrm{~mL} \mathrm{~m}^{-2} 24 \mathrm{~h}^{-1}$, which is a typical value of high barrier coatings 315 used within the food packaging field. In addition, the $\mathrm{H}_{0}, \mathrm{H}_{3}, \mathrm{H}_{2}$, and $\mathrm{H}_{1}$ coatings exhibited a 316 similar trend, while the $\mathrm{H}_{0.5}$ hybrid coating behaved more similarly to the plastic substrate, at 317 least in the $0 \%-40 \% \mathrm{RH}$ range. The behavior of the $\mathrm{H}_{0.75}$ coating was similar to that of the 
318 plastic substrate at up to $40 \% \mathrm{RH}$, while it followed the same trend of the other coatings above 319 that point. These results clearly demonstrate that increasing the inorganic concentration had a 320 detrimental effect on the barrier properties of the final structure. This is in contrast to what was 321 expected, as it is well established that decreasing the $\mathrm{O} / \mathrm{I}$ ratio should improve the barrier 322 properties, assuming oxygen permeation occurs mainly or exclusively within the organic phase 323 (34). Causes linked to the physical changes induced by the increase in the O/I ratio on the overall 324 organization of the final coatings should be invoked to explain the obtained results.

The optical microscope images of the surface of the hybrid coatings (Figure 8) allowed for 326 some important observations, otherwise unattainable by simple visual inspection of the samples 327 (also due to the very high transparency of the films). Besides the pure pullulan coating, whose 328 high surface smoothness has already been reported elsewhere (35), the only sample with an even, 329 smooth surface, with no evidence of either cracks or pinholes, was the $\mathrm{H}_{3}$ hybrid. The surface of 330 the $\mathrm{H}_{2}$ sample exhibited some bright veins, which appeared to be organized in a denser and more 331 regular pattern in the $\mathrm{H}_{1}$ sample, as clearly highlighted by the topographical image. Whether 332 these veins are due to molecular re-organization or whether they represent the first sign of 333 surface failure is still not clear. In the $\mathrm{H}_{0.75}$ and $\mathrm{H}_{0.5}$ samples, the inherent rigidity of the silica 334 network prevailed on the innate flexibility of pullulan, insomuch as ruptures occurred on the 335 coating surface, particularly evident in sample $\mathrm{H}_{0.5}$. These ruptures appeared as parallel cracks of $336 \sim 10 \mu \mathrm{m}$ width and separated by $\sim 100 \mu \mathrm{m}$ one from the other, suggesting that they probably 337 formed along the tracks of the wires of the rod used to lay the coating dispersion on the plastic 338 substrate. The main reason presumably lies in the mechanical stresses triggered by the shrinking 339 of the matrix during the solvent evaporation step, as also reported by many authors $(29,36,37)$. 
Ruptures and cracks dramatically affected the oxygen barrier properties of the final

341

342

343

344

345

346

347

348

349

350

351

352

353

354

355

356

357

358

359

360

361

362

structure for two main reasons. On the one hand, they acted as gaps where the permeation of oxygen was no longer governed by the physicochemical properties of the coating, but by the performance of the plastic substrate. This is why the oxygen transmission rate of the coatings increased with decreasing $\mathrm{O} / \mathrm{I}$ ratios, approaching the value of the underlying PET substrate. On the other hand, it is well known that cracks and pinholes play an important role as amplifiers for water vapor penetration inside the coating network, thus accelerating the swelling phenomenon, which in turn will affect the final oxygen barrier properties. This is probably the main reason why all of the hybrid coatings tested in this work completely lost their barrier performance at $80 \%$ relative humidity. Therefore, in light of the obtained results, it can be said that although all of the formulations tested led to some extent to a reduction in OTR values (ranging from 99\% to $\sim 27 \%$ ) compared to the PET substrate, the hybrid coating with the lowest silica content achieved the best performance, fully comparable to those reported in the literature for similar organic/silica hybrid coatings, at least up to $60 \%$ relative humidity $(24,34)$.

In conclusion, this study has demonstrated that pullulan, in combination with TEOS, can be profitably used to generate oxygen barrier hybrid coatings. As demonstrated by TEM and spectrometric analyses, the formation of a hybrid network through self-assembly is driven by inter-molecular hydrogen bond formation at the interfaces of end-capped silanol groups generated from TEOS and of the pendant hydroxyl groups of the pullulan backbone. However, it is necessary to use the lowest amount of silica to avoid extensive cracking of the coatings, thus preserving the 'protective' effect of the inorganic phase toward the surrounding humidity. Eventually, this would allow the achievement of OTR values fully comparable to the current solutions available on the market, making pullulan, in association with silica, a viable alternative 
363 to the commonly used organic polymers derived from petrol for the development of oxygen 364 barrier coatings, especially as intended for food packaging applications. Although this new application may be beneficial with regard to expanding the market 366 penetration of pullulan, its cost still represents a remarkable obstacle. Based on the latest 367 quotation of each component, the unit cost of PET film $(12 \mu \mathrm{m})$ coated with the $\mathrm{H}_{3}$ formulation 368 is estimated at $3.7 € / \mathrm{kg}$, which is higher than the sale price of the today's oil-derived alternatives 369 (e.g., the price of PET $12 \mu \mathrm{m}$ coated with PVOH $1.0 \mu \mathrm{m}$ is $\sim 2.6 € / \mathrm{kg}$ ).

370

371

372

373

375

376

377

378

379

380 
381

382

383

384

385

387

388

389

390

391

392

393

394

395

396

397

398

399

400

401

402

403

\section{Literature cited}

(1) Leathers, T. D. Pullulan. In Polysaccharides II: Polysaccharides from Eukaryotes; Vandamme, E. J.; De Baets, S.; Steinblichel, A., Eds.; Wiley-VCH: Weinheim, Germany, 2002; Vol. 6, pp. 1-35.

(2) Buliga, G. S.; Brant, D. A. Temperature and molecular weight dependence of the unperturbed dimensions of aqueous pullulan. Int. J. Biol. Macromol. 1987, 9, 71-76.

(3) Dais, P.; Vlachou, S.; Taravel, F. ${ }^{13} \mathrm{C}$ nuclear magnetic relaxation study of segmental dynamics of the heteropolysaccharide pullulan in dilute solutions. Biomacromolecules 2001, 2, 1137-1147.

(4) Shingel, K. I. Current knowledge on biosynthesis, biological activity, and chemical modification of the exopolysaccharide, pullulan. Carbohyd. Res. 2004, 339, 447-460.

(5) Yuen, S. Pullulan and its applications. Process Biochem. 1974, 9, 7-9.

(6) Leathers, T. D. Biotechnological production and applications of pullulan. Appl. Microbiol. Biotechnol. 2003, 62, 468-473.

(7) Trinetta, V.; Cutter, C. N.; Floros, J. D. Effects of ingredient composition on optical a mechanical properties of pullulan film for food-packaging applications. Food Sci. Technol.-Leb. 2011, 44, 2296-3301.

(8) Islam, M. S.; Akter, N.; Karim, M. R. Preparation of superhydrophobic membranes by electrospinning of fluorinated silane functionalized pullulan. Colloid. Surface. A 2010, $362,117-120$.

(9) Sanchez-Garcia, M.D.; Hilliou, L.; Lagaron, J. M. Nanobiocomposites of carrageenan, zein, and mica of interest in food packaging and coating applications. J. Agric. Food Chem. 2010, 58, 6884-6894. 
(10) Ben Arfa, A.; Preziosi-Belloy, L.; Chalier, P.; Gontard, N. Antimicrobial paper based on a soy protein isolate or modified starch coating including carvacrol and cinnamaldehyde. $J$. Agric. Food Chem. 2007, 55, 2155-2162.

(11) Han, J.; Salmieri, S.; Le Tien, C.; Lacroix, M. Improvement of water barrier property of paperboard by coating application with biodegradable polymers. J. Agric. Food Chem. 2010, 58, 3125-3131.

(12) Farris, S.; Schaich, K. M.; Liu, L. S.; Piergiovanni, L.; Yam, K. L. Development of polyioncomplex hydrogels as an alternative approach for the production of bio-based polymers for food packaging applications: a review. Trends Food Sci. Tech. 2009, 20, 316-332.

(13) Liu, L. S.; Finkenstadt, V. L.; Liu, C.-K.; Jin, T.; Fishman, M. L.; Hicks, K. B. Preparation of poly(lactic acid) and pectin composite films intended for applications in antimicrobial packaging. J. Appl. Polym. Sci. 2007, 106, 801-810.

(14) Farris, S.; Introzzi, L.; Piergiovanni, L. Evaluation of a bio-coating as a solution to improve barrier, friction and optical properties of plastic films. Packag. Technol. Sci. 2009, 22, 69-83.

(15) Guilbert, S.; Gontard, N. Agro-polymers for edible and biodegradable films: review of agricultural polymeric materials, physical and mechanical characteristics. In Innovations in Food Packaging; Han, J. H., Ed.; Elsevier Academic Press: New York, NY, 2005; pp. $263-274$.

(16) Brinker, C. J. Hydrolysis and condensation of silicates: effects on structure. J. Non-Cryst. Solids 1988, 100, 31-50.

(17) Brinker, C. J.; Scherer, J. W. Sol-Gel Science: The Physics and Chemistry of Sol-Gel Processing. Academic Press: New York, NY, 1990. 
427 (18) Aelion, R.; Loebel, A.; Eirich, F. Hydrolysis of ethyl silicate. J. Am. Chem. Soc. 1950, 72, $5705-5712$.

429

430

431

432

433

434

435

436

437

438

439

440

441

442

443

444

445

446

447

448

449

(19) Geppi, M.; Mollica, G.; Borsacchi, S.; Marini, M.; Toselli, M.; Pilati, F. Solid state NMR characterization of PE-PEG/Silica hybrid materials prepared by microwave-assisted solgel process. J. Mater. Res. 2007, 22, 3516-3525.

(20) Bandyopadhyay, A.; De Sarkar, M.; Bhowmick, A. Poly(vinyl alcohol)/silica hybrid nanocomposites by sol-gel technique: synthesis and properties. J. Mater. Sci. 2005, 40, $5233-5241$.

(21) Minelli, M.; De Angelis, M. G.; Doghieri, F.; Rocchetti, M.; Montenero, A. Barrier properties of organic-inorganic hybrid coatings based on polyvinyl alcohol with improved water resistance. Polym. Eng. Sci. 2010, 50, 144-153.

(22) ASTM. Standard practices for producing films of uniform thickness of paint, varnish, and related products on test panels. Designation D823-07. American Society for Testing and Materials. West Conshohocken PA 19428 - 2959 United States.

(23) Bell, L. N.; Labuza, T. P. Practical Aspects of Moisture Sorption Isotherm Measurement and Use, 2nd ed.; AACC, Ed. Egan Press: Egan, MN, 2000.

(24) ASTM. Standard Test Method for oxygen gas transmission rate through plastic film and sheeting using various sensors. Designation F 2622 - 08. American Society for Testing and Materials. West Conshohocken PA 19428 - 2959 United States.

(25) Lee, D. S.; Yam, K. L.; Piergiovanni, L. Food Packaging Science and Technology. CRC Press: Boca Raton, FL, 2008.

(26) Limpo, J.; Rubio, J.; Oteo, J. L. Estudio por FT-IR de la hidrolisis del tetraetilortosilicato. Bol. Soc. Esp. Ceram. V. 1993, 1, 31-35. 
450 (27) Shingel, K. I. Determination of structural peculiarities of dexran, pullulan and $\gamma$-irradiated 451 pullulan by Fourier-transform IR spectroscopy. Carbohyd. Res. 2002, 337, 1445-1451.

452

453

454

455

456

457

458

459

460

461

462

463

464

465

466

467

468

469

470

471
(28) Uragami, T.; Okazaki, K.; Matsugi, H.; Miyata, T. Structure and permeation characteristics of an aqueous ethanol solution of organic-inorganic hybrid membranes composed of poly(vinyl alcohol) and tetraethoxysilane. Macromolecules 2002, 35, 9156-9163.

(29) Lee, S.-Y.; Lee, J.-D.; Yang, S.-M. Preparation of silica-based hybrid materials coated on polypropylene film. J. Mater. Sci. 1999, 34, 1233-1241.

(30) Tong, Q.; Xiao, Q.; Lim, L.-T. Preparation and properties of pullulan-alginatecarboxymethylcellulose blend films. Food Res. Int. 2008, 41, 1007-1014.

(31) Bhagat, S. D.; Hirashima, H.; Rao, A. V. Low density TEOS based silica aerogels using methanol solvent. J. Mater. Sci. 2007, 42, 3207-3214.

(32) Auras, R.; Harte, B.; Selke, S. Effect of water on the oxygen barrier properties of poly (ethylene terephthalate) and polylactide films. J. Appl. Polym. Sci. 2004, 92, 1790-1803.

(33) Hu, Y. S.; Mehta, S.; Schiraldi, D. A.; Hiltner, A.; Baer, E. Effect of water sorption on oxygen-barrier properties of aromatic polyamides. J. Polym. Sci. Pol. Phys. 2005, 43, $1365-1381$.

(34) Minelli, M.; De Angelis, M. G.; Doghieri, F.; Marini, M.; Toselli, M.; Pilati, F. Oxygen permeability of novel organic-inorganic coatings: I. Effects of organic-inorganic ratio and molecular weight of the organic component. Eur. Polym. J. 2008, 44, 2581-2588.

(35) Farris S.; Introzzi L.; Biagioni, P.; Holz, T.; Schiraldi, A.; Piergiovanni L. Wetting of biopolymer coatings: contact angle kinetics and image analysis investigation. Langmuir 2011, 27, 7563-7574. 
472 (36) Fabbri, P.; Singh, B.; Leterrier, Y.; Manson, J.-A. E.; Messori, M.; Pilati, F. Cohesive and 473 adhesive properties of polycaprolactone/silica hybrid coatings on poly (methyl 474 methacrylate) substrates. Surf. Coat. Tech. 2006, 200, 6706-6712.

475 (37) Kim, S.-W. Preparation and barrier property of poly (vinyl alcohol)/SiO $\mathrm{S}_{2}$ hybrid coating 476 films. Korean J. Chem. Eng. 2008, 25, 1195-1200.

477

478

479

480

481

482

483

484

485

486

487

488

489

490

491

492

493

494 
497 Table 1. Formulation, thickness and residual moisture of the coatings tested in this work

\begin{tabular}{ccccccc}
\hline Exp. $\mathrm{n}^{\circ}$ & $\begin{array}{c}\text { Coded } \\
\text { name }\end{array}$ & $\begin{array}{c}\text { Pullulan } \\
(\text { wt-\% })\end{array}$ & $\begin{array}{c}\mathrm{Si}(\mathrm{OH})_{4} \\
(\mathrm{wt}-\%)\end{array}$ & $\begin{array}{c}\left(\mathrm{O} / \mathrm{I}^{*}\right) \\
\text { ratio }\end{array}$ & $\begin{array}{c}\text { Coating } \\
\text { thickness }(\mu \mathrm{m})\end{array}$ & $\begin{array}{c}\text { Residual } \\
\text { moisture }(\%)\end{array}$ \\
\hline 1 & $\mathrm{H}_{0}$ & 10 & 0 & $/$ & $1.27 \pm 0.12^{\mathrm{a}}$ & $2.44 \pm 0.05^{\mathrm{A}}$ \\
2 & $\mathrm{H}_{3}$ & 7.5 & 2.5 & 3 & $1.37 \pm 0.18^{\mathrm{ab}}$ & $2.61 \pm 0.02^{\mathrm{AB}}$ \\
3 & $\mathrm{H}_{2}$ & 6.66 & 3.33 & 2 & $1.31 \pm 0.07^{\mathrm{ab}}$ & $2.78 \pm 0.04^{\mathrm{BC}}$ \\
4 & $\mathrm{H}_{1}$ & 5 & 5 & 1 & $1.26 \pm 0.14^{\mathrm{ab}}$ & $2.71 \pm 0.06^{\mathrm{CD}}$ \\
5 & $\mathrm{H}_{0.75}$ & 4.3 & 5.7 & 0.75 & $1.19 \pm 0.08^{\mathrm{ab}}$ & $2.57 \pm 0.03^{\mathrm{D}}$ \\
6 & $\mathrm{H}_{0.5}$ & 3.33 & 6.66 & 0.5 & $1.15 \pm 0.09^{\mathrm{b}}$ & $2.66 \pm 0.04^{\mathrm{E}}$ \\
\hline
\end{tabular}

Table 2. Parameters obtained from the fitting of the experimental sorption data with the GAB model

\begin{tabular}{lcccc}
\hline Coating type & $\mathrm{R}^{2}$ & $M_{0}^{*}$ & $C$ & $K$ \\
\cline { 2 - 5 } $\mathrm{H}_{0}$ (pure pullulan) & 0.991 & 0.78 & 0.03 & 1.06 \\
$\mathrm{H}_{3}(\mathrm{O} / \mathrm{I}=3)$ & 0.997 & 0.53 & 0.03 & 1.07 \\
$\mathrm{H}_{2}(\mathrm{O} / \mathrm{I}=2)$ & 0.995 & 0.19 & 0.08 & 1.04 \\
\hline
\end{tabular}


Table 3. Oxygen Transmission Rate (OTR) of PET, and PET coated with pullulan and the hybrid coatings at five different relative humidity gradients and $23^{\circ} \mathrm{C}$

\begin{tabular}{|c|c|c|c|c|c|}
\hline \multirow{3}{*}{ Sample } & \multicolumn{5}{|c|}{ Oxygen Transmission Rate $\left(\mathrm{mL} \mathrm{m}^{-2} 24 \mathrm{~h}^{-1}\right)$} \\
\hline & \multicolumn{5}{|c|}{ Relative humidity gradient $(\Delta \mathrm{RH}, \%)$} \\
\hline & 0 & 20 & 40 & 60 & 80 \\
\hline PET & $\begin{array}{l}165.20^{\mathrm{a}} \\
( \pm 1.96)\end{array}$ & $\begin{array}{l}147.10^{\mathrm{g}} \\
( \pm 1.65)\end{array}$ & $\begin{array}{c}140.05^{1} \\
( \pm 0.873)\end{array}$ & $\begin{array}{l}130.30^{\mathrm{s}} \\
( \pm 1.05)\end{array}$ & $\begin{array}{l}126.08^{x} \\
( \pm 2.14)\end{array}$ \\
\hline $\mathrm{PET} / \mathrm{H}_{0}$ & $\begin{array}{c}4.92^{\mathrm{b}} \\
( \pm 0.13)\end{array}$ & $\begin{array}{c}5.95^{\mathrm{h}} \\
( \pm 0.07)\end{array}$ & $\begin{array}{l}9.98^{\mathrm{m}} \\
( \pm 0.71)\end{array}$ & $\begin{array}{c}54.60^{\mathrm{t}} \\
( \pm 0.38)\end{array}$ & $\begin{array}{c}106^{\mathrm{y}} \\
( \pm 0.74)\end{array}$ \\
\hline $\mathrm{PET} / \mathrm{H}_{3}$ & $\begin{array}{c}0.96^{\mathrm{c}} \\
( \pm 0.03)\end{array}$ & $\begin{array}{c}1.12^{\mathrm{c}} \\
( \pm 0.01)\end{array}$ & $\begin{array}{c}2.79^{\mathrm{n}} \\
( \pm 0.19)\end{array}$ & $\begin{array}{c}40.90^{\mathrm{q}} \\
( \pm 0.20)\end{array}$ & $\begin{array}{c}102^{\mathrm{Z}} \\
( \pm 0.30)\end{array}$ \\
\hline $\mathrm{PET} / \mathrm{H}_{2}$ & $\begin{array}{c}5.23^{\mathrm{b}} \\
( \pm 0.24)\end{array}$ & $\begin{array}{c}6.48^{\mathrm{i}} \\
( \pm 0.05)\end{array}$ & $\begin{array}{l}11.40^{\circ} \\
( \pm 0.43)\end{array}$ & $\begin{array}{c}54.20^{t} \\
( \pm 0.22)\end{array}$ & $\begin{array}{c}105^{\mathrm{y}} \\
( \pm 0.21)\end{array}$ \\
\hline $\mathrm{PET} / \mathrm{H}_{1}$ & $\begin{array}{l}13.30^{\text {do }} \\
( \pm 0.39)\end{array}$ & $\begin{array}{c}12.80^{\mathrm{d}} \\
( \pm 0.30)\end{array}$ & $\begin{array}{c}15.40^{\mathrm{p}} \\
( \pm 0.45)\end{array}$ & $\begin{array}{l}58.30^{\mathrm{u}} \\
( \pm 0.12)\end{array}$ & $\begin{array}{c}111^{\mathrm{A}} \\
( \pm 0.22)\end{array}$ \\
\hline $\mathrm{PET} / \mathrm{H}_{0.75}$ & $\begin{array}{c}31.90^{\mathrm{e}} \\
( \pm 1.21)\end{array}$ & $\begin{array}{c}33.90^{\mathrm{j}} \\
( \pm 0.40)\end{array}$ & $\begin{array}{l}41.30^{\mathrm{q}} \\
( \pm 1.11)\end{array}$ & $\begin{array}{l}85.70^{\mathrm{V}} \\
( \pm 0.43)\end{array}$ & $\begin{array}{c}110^{\mathrm{A}} \\
( \pm 0.88)\end{array}$ \\
\hline $\mathrm{PET} / \mathrm{H}_{0.5}$ & $\begin{array}{c}82.30^{\mathrm{f}} \\
( \pm 1.97)\end{array}$ & $\begin{array}{c}65.50^{\mathrm{k}} \\
( \pm 0.19)\end{array}$ & $\begin{array}{c}63.80^{\mathrm{r}} \\
( \pm 1.08)\end{array}$ & $\begin{array}{l}92.70^{\mathrm{w}} \\
( \pm 0.46)\end{array}$ & $\begin{array}{c}111^{\mathrm{A}} \\
( \pm 1.22)\end{array}$ \\
\hline
\end{tabular}




\section{Figure captions}

529

530

531

532

533 534 formation.

535

536

537

538

539

540

541

542

543

544

545

546

547

548

549

550

551 coating.

2
preparation.

Figure 1. Representative chemical structure of pullulan as repeating units of maltotriose.

Figure 2. Schematic representation of the reactions expected in the sol-gel hybrid network

Figure 3. Optical microscope cross-section of PET film coated with a pullulan-silica hybrid

Figure 4. FTIR-ATR spectra of pullulan (a), reacted TEOS (b) and pullulan ( $\square$ ), reacted TEOS (O), and hybrid coatings $\mathrm{H}_{0.5}(-), \mathrm{H}_{0.75}(\cdots \cdots \cdot), \mathrm{H}_{1}(---), \mathrm{H}_{2}(-), \mathrm{H}_{3}(-)$ within 1300 $\mathrm{cm}^{-1}-850 \mathrm{~cm}^{-1}$ (c) and $3800 \mathrm{~cm}^{-1}-3000 \mathrm{~cm}^{-1}$ (d) spectral ranges.

Figure 5. Sorption isotherm mean curves of pure pullulan coating ( $\square$ experimental data; - - - predicted data) and hybrid coatings $\mathrm{H}_{3}(\diamond$ experimental data; - predicted data $)$ and $\mathrm{H}_{2}(\triangle$ experimental data; — predicted data) at $25^{\circ} \mathrm{C}$. The predicted data were obtained by fitting the experimental points with the GAB model (Equation 2 in the text).

Figure 6. TEM images of reacted TEOS (a), pullulan (b), and the hybrid coating $\mathrm{H}_{1}$ (c and d) at two different magnifications. All images are from 0.5 wt- $\%$ hybrid dispersions 1 hour after 
552 Figure 7. OTR evolution for PET, pullulan, and the five hybrid coatings over the $0 \%-80 \%$ 553 relative humidity gradient range at $23^{\circ} \mathrm{C}$.

554

555 Figure 8. Optical microscope images of coating surfaces at 10× magnification in normal (left) 556 and topographical (right) modes (with the exception of sample $\mathrm{H}_{0.75}$, where a $20 \times$ magnification 557 of the normal mode image is reported).

558

559

560

561

562

563

564

565

566

567

568

569

570

571

572

573

574

575

576 


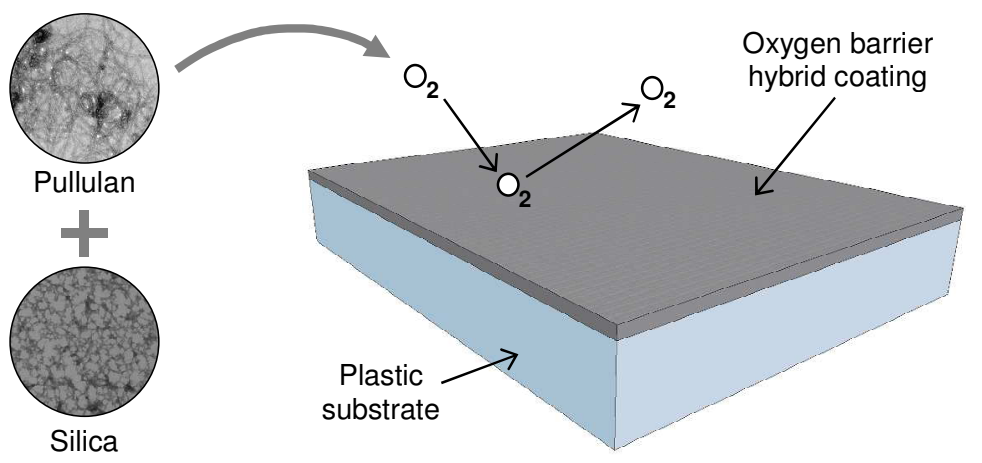

588 Table of Content categories:

589 1. Chemical Changes Induced by Processing/Storage

590

2. Environmental Chemistry

591

3. Chemical Aspects of Biotechnology/Molecular Biology 


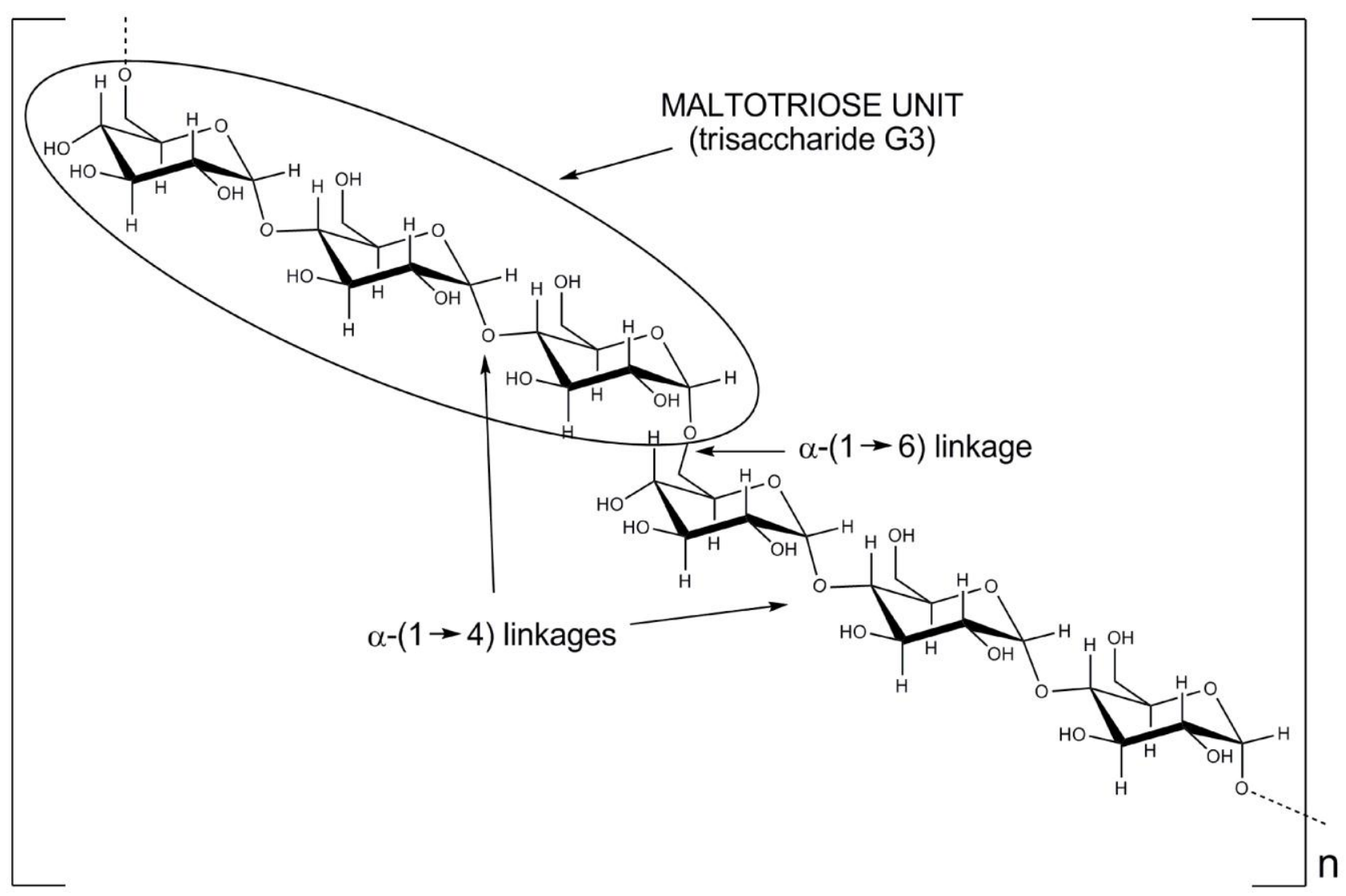

Figure 1. Representative chemical structure of pullulan as repeating units of maltotriose. 


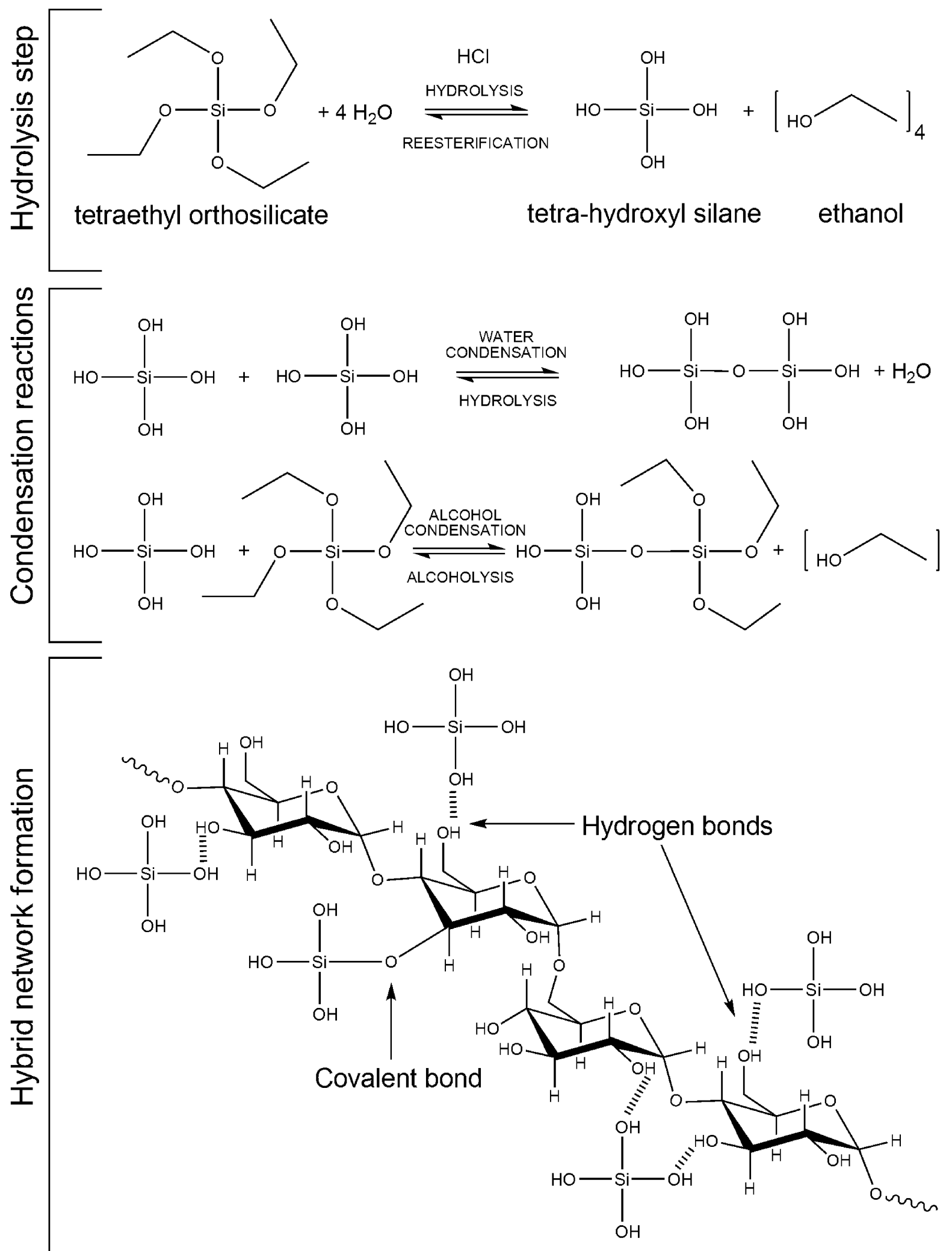

Figure 2. Schematic representation of the reactions expected in the sol-gel hybrid network formation. 


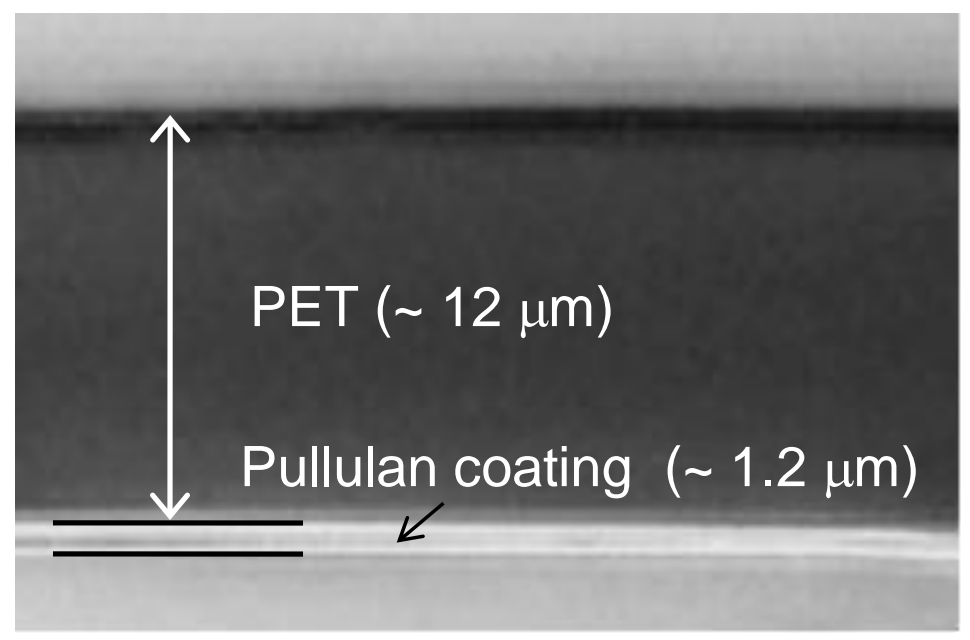

Figure 3. Optical microscope cross-section $(50 \times)$ of PET film coated with a pullulan-silica hybrid coating. 

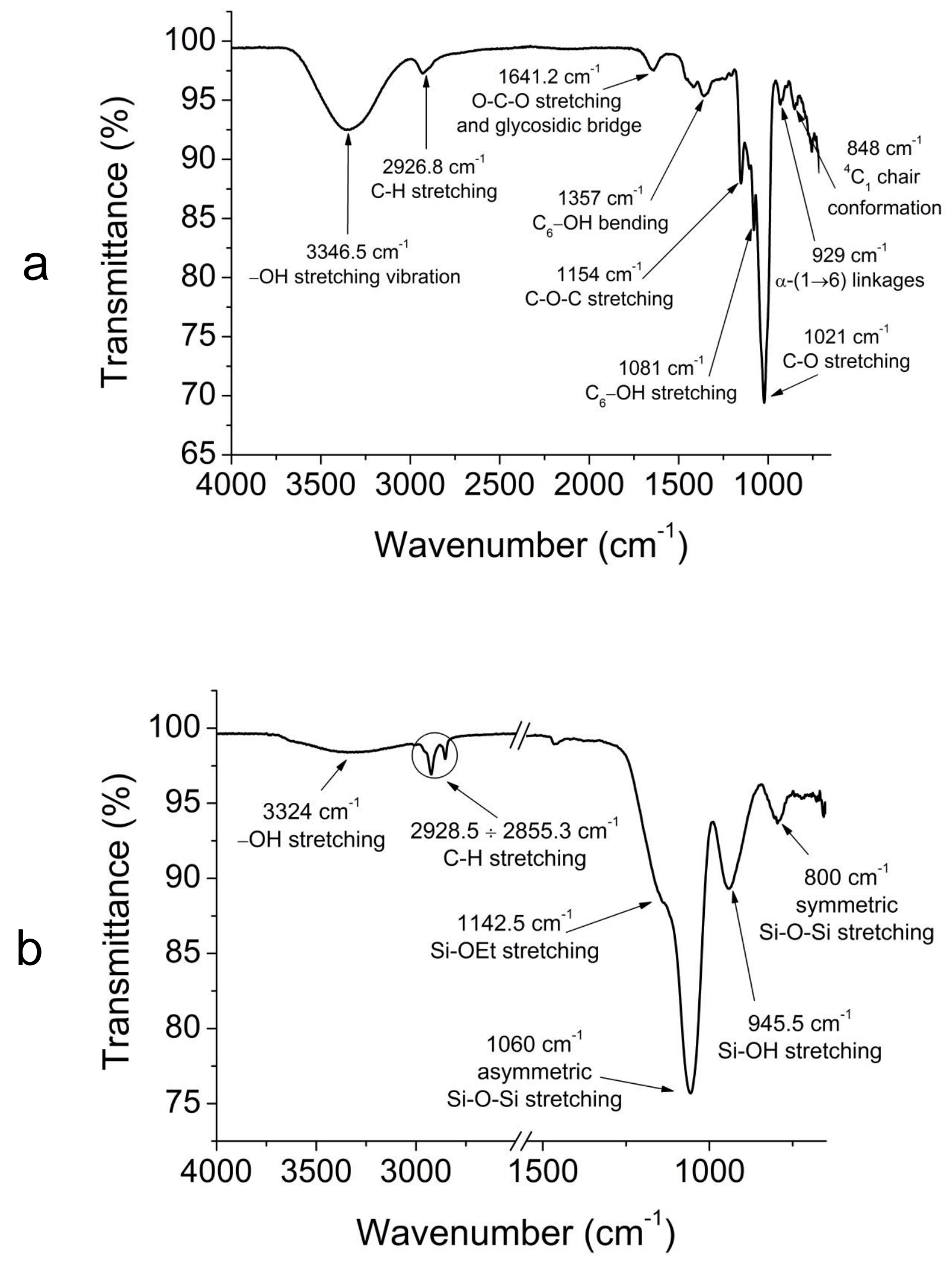

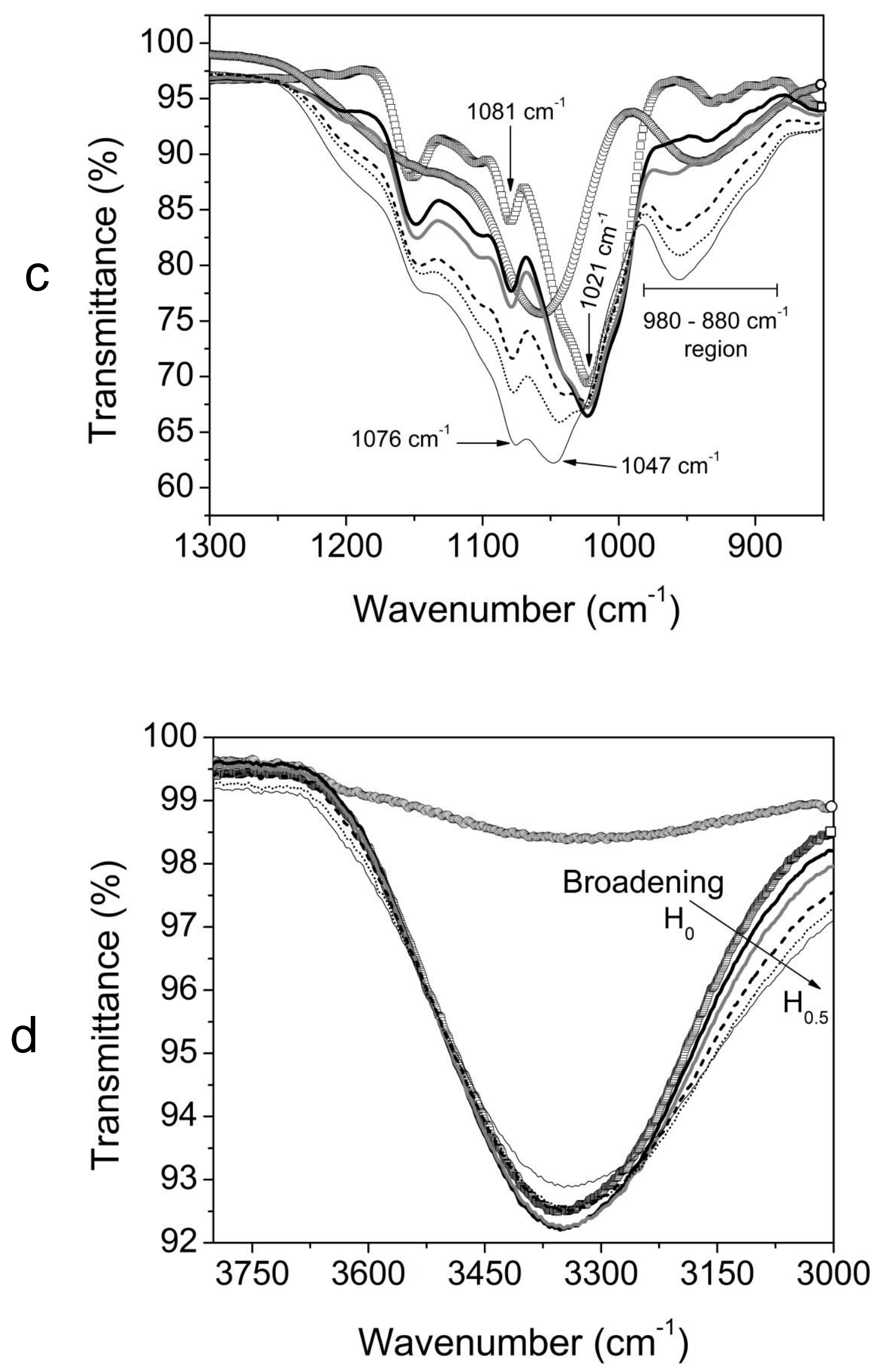

Figure 4. FTIR-ATR spectra of pullulan (a), reacted TEOS (b) and pullulan ( $\square$ ), reacted TEOS (O), and hybrid coatings $\mathrm{H}_{0.5}(-), \mathrm{H}_{0.75}(\cdots \cdots .),. \mathrm{H}_{1}(----), \mathrm{H}_{2}(-), \mathrm{H}_{3}(-)$ within $1300 \mathrm{~cm}^{-1}-$ $850 \mathrm{~cm}^{-1}(\mathrm{c})$ and $3800 \mathrm{~cm}^{-1}-3000 \mathrm{~cm}^{-1}(\mathrm{~d})$ spectral ranges. 


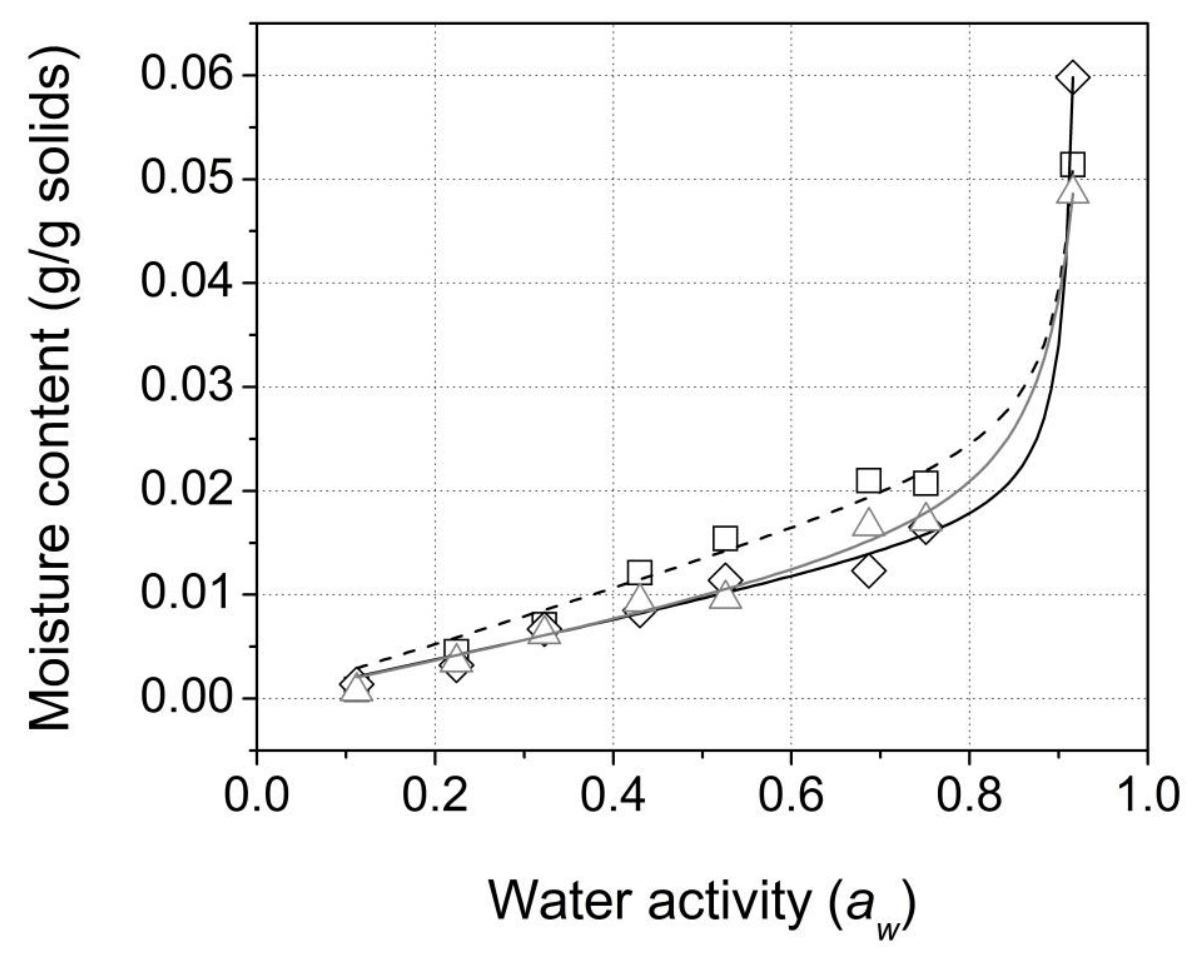

Figure 5. Sorption isotherm mean curves of pure pullulan coating ( $\square$ experimental data; - - - predicted data) and hybrid coatings $\mathrm{H}_{3}\left(\diamond\right.$ experimental data; - predicted data) and $\mathrm{H}_{2}(\triangle$ experimental data; — predicted data) at $25^{\circ} \mathrm{C}$. The predicted data were obtained by fitting the experimental points with the GAB model (Equation 2 in the text). 

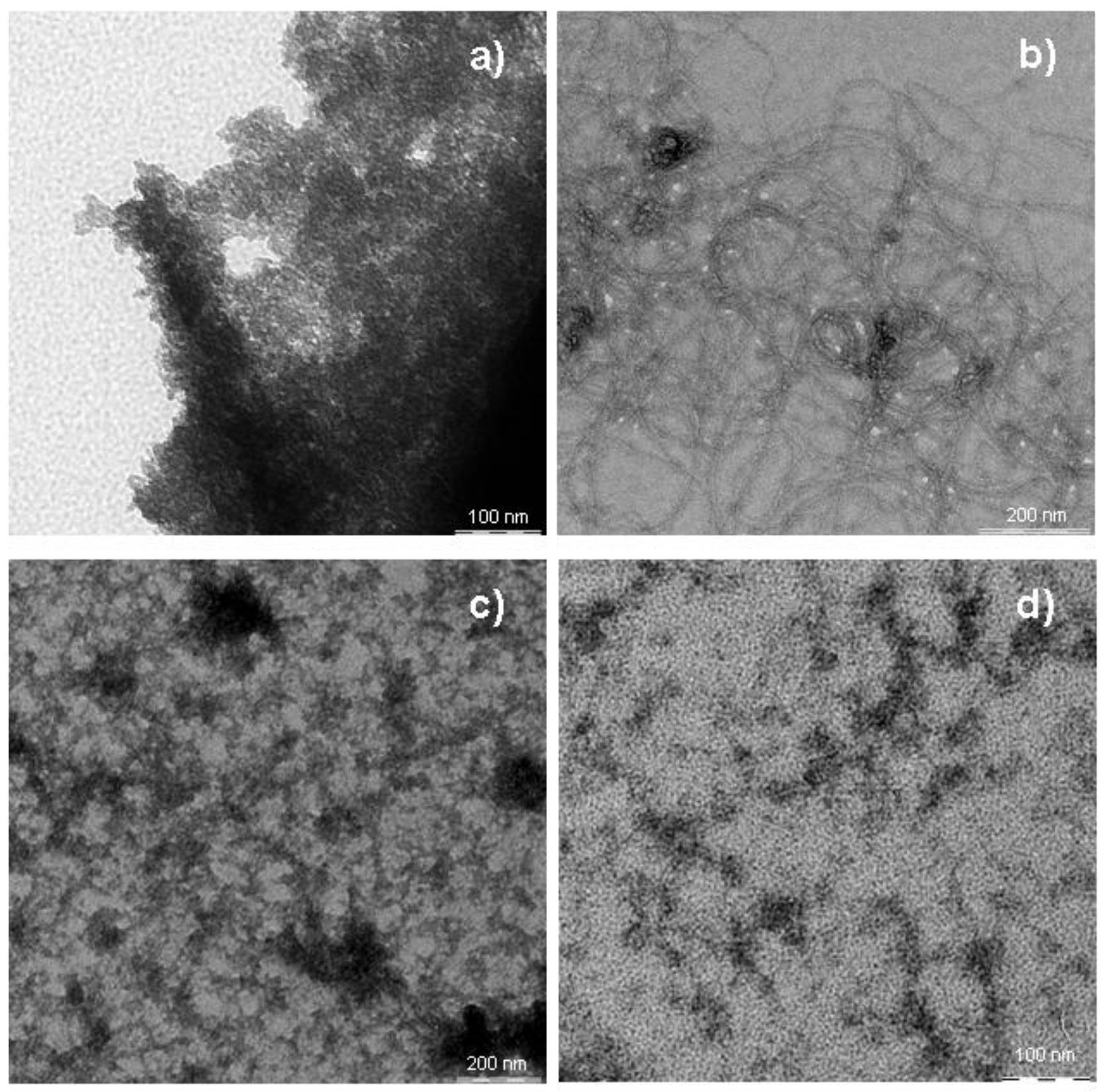

Figure 6. TEM images of reacted TEOS (a), pullulan (b), and the hybrid coating $\mathrm{H}_{1}$ (c and d) at two different magnifications. All images are from $0.5 \mathrm{wt}-\%$ hybrid dispersions 1 hour after preparation. 


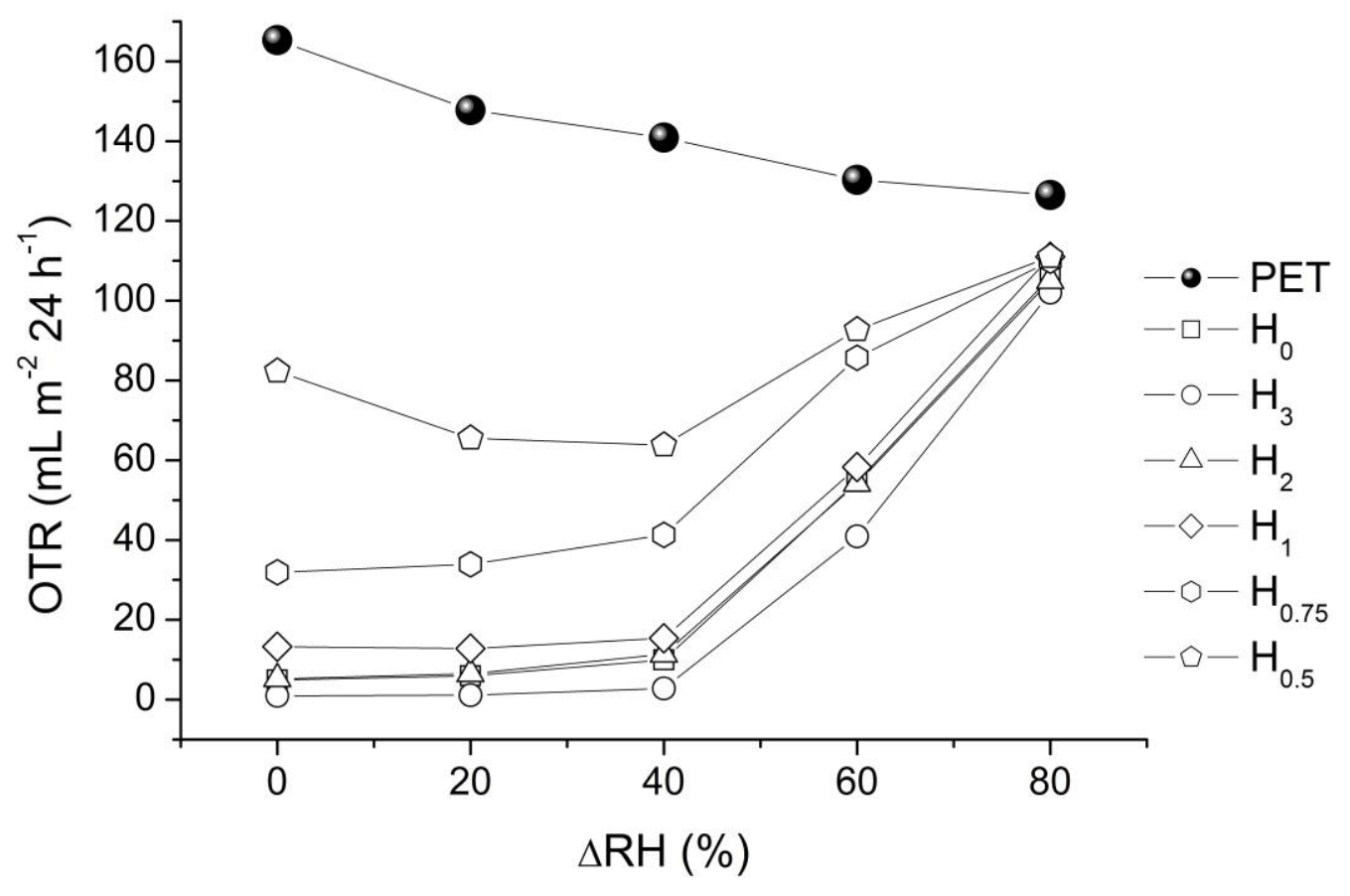

Figure 7. OTR evolution for PET, pullulan, and the five hybrid coatings over the $0 \%-80 \%$ relative humidity gradient range at $23^{\circ} \mathrm{C}$. 


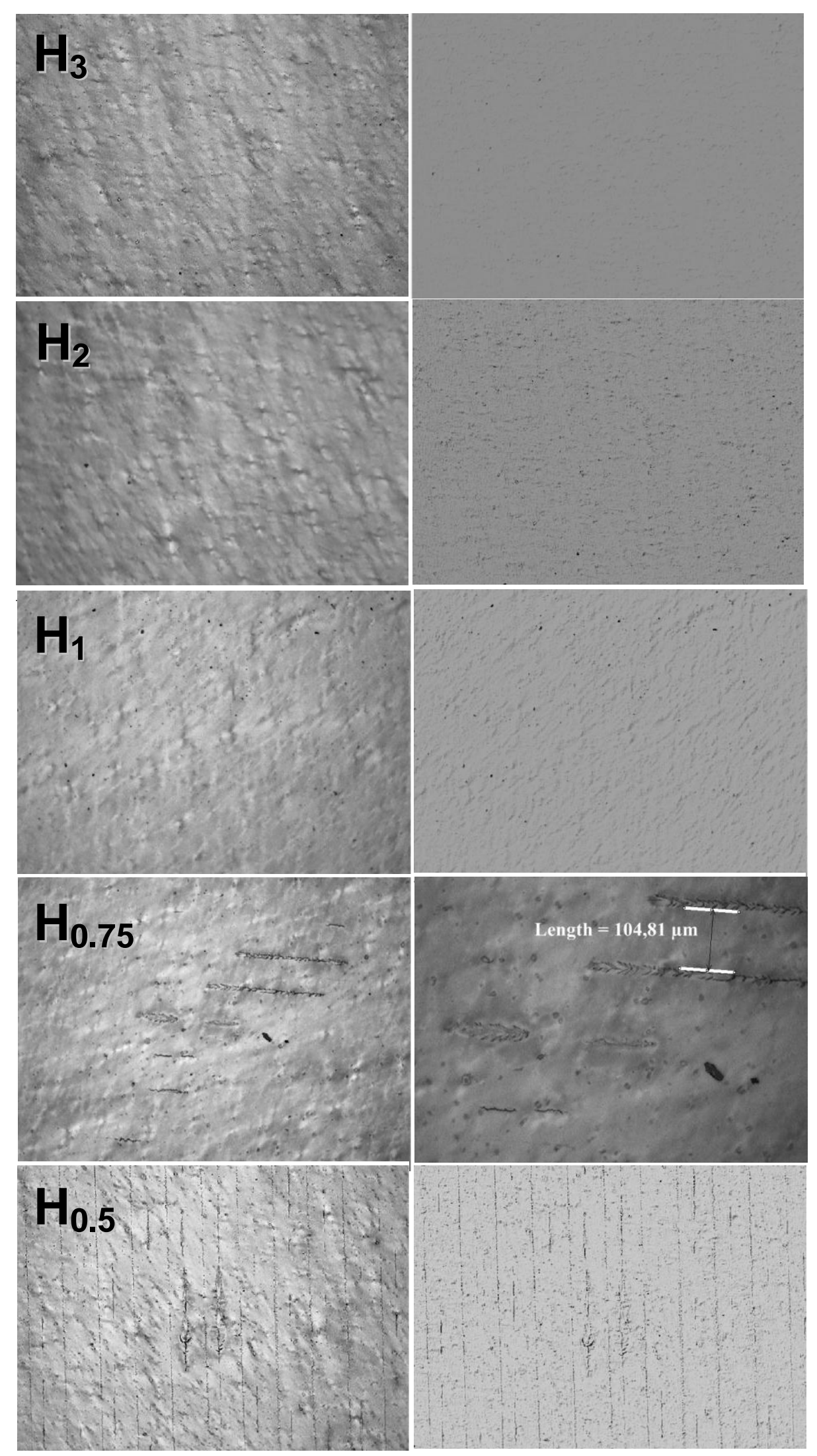

Figure 8. Optical microscope images of coating surfaces at $10 \times$ magnification in normal (left) and topographical (right) modes (with the exception of sample $\mathrm{H}_{0.75}$, where a $20 \times$ magnification of the normal mode image is reported). 